\title{
GERMINAÇÃO DE SEMENTES DE NIM (Azadirachta indica A. JUSS) EM FUNÇÃO DO TIPO DE COLETA E DA COLORAÇÃO DOS FRUTOS
}

\begin{abstract}
PEDROSO $^{71}$, Luciana
AZEREDO $^{72}$, Gilvaneide Alves de VANZOLINI ${ }^{73}$, Silvelena

Recebido em: 2008-08-12

Aprovado em: $2008-08-28$

ISSUE DOI: $10.3738 / 1982.2278 .132$

RESUMO: O nim é uma espécie arbórea pertencente à família Meliaceae, cujas sementes, em condições normais, apresentam baixa longevidade. Este trabalho teve como objetivo avaliar a germinação de sementes de nim em função do tipo de coleta de seus frutos, se no chão ou na árvore, e em função da coloração. Os tratamentos foram: T1- na árvore apresentando coloração verde; T2- no chão, apresentando polpa; T3- no chão com resquícios de polpa; T4- na árvore de coloração amarela; T5- na árvore em diferentes colorações. Foram determinados os teores de água dos frutos e sementes e, posteriormente, realizado o teste de germinação à temperatura alternada de $20-35^{\circ} \mathrm{C}$. Utilizaram-se quatro repetições de vinte sementes por tratamento, com exceção do tratamento de coloração amarela que possuiu quatro repetições de quinze sementes. As características avaliadas foram percentagem e índice de velocidade de emergência (IVE), e percentagem de plântulas normais. Os resultados revelaram que os as sementes de nim oriundas de frutos coletados no chão, que se apresentavam parcialmente com polpa, exibiram maior qualidade fisiológica.
\end{abstract}

\section{Palavras-chave: Maturação. Qualidade fisiológica. Emergência}

SUMMARY: The neem tree is a species belonging to the family Meliaceae, whose seed, under normal conditions, have low longevity. This study aimed to evaluate the germination of seeds of neem depending on the type of collection of its fruits, if the ground or in the tree and depending on the colour. The treatments were: T1giving tree in green tint, T2-giving flesh on the floor; T3-on the floor with remnants of flesh; T4-the tree of yellow; T5-the tree in different colours. The moisture content fruit and seeds were determinate. The germinated test in germinator the alternating temperature of $20-30^{\circ} \mathrm{C}$ was conducted. It was used four replicates of twenty seeds per treatment, except for treatment of yellow that owned four replicates of fifteen seed. The characteristics were evaluated percentage and speed of emergence index (IVE) and percentage of normal seedlings. The results showed that the seeds of the neem fruits collected from the ground, that were partially with pulp, showed greater physiological quality.

Keywords: Maturation. Physiological quality. Emergence

\footnotetext{
${ }^{71}$ Aluna de pós-graduação. E-mail: lupbio@ yahoo.com.br

${ }_{72}$ Aluna de pós-graduação em Produção Vegetal, Unesp-Jaboticabal. E-mail: azeredogil@ yahoo.com.br

${ }^{73}$ Profa. Dra. Pós-graduação em Produção Tecnologia de Sementes, UNESP-Jaboticabal. Profa. Dra. Graduação Agronomia, FEI/FAFRAM, Ituverava. E-mail: sv.segato@ carol.com.br
} 


\section{INTRODUÇÃO}

Oriundo da Índia, o nim (Azadirachta indica) é uma espécie pertencente à família Meliaceae, cuja árvore, de rápido crescimento, chega a atingir de 10 a $15 \mathrm{~m}$ de altura, podendo chegar a $25 \mathrm{~m}$, dependendo do tipo de solo e das condições climáticas favoráveis ao seu desenvolvimento (MARTINEZ, 2002; SOON; BOTTRELL, 1994). É cultivada atualmente nos Estados Unidos, Austrália, países da África e América Central. É utilizada há mais de 2 mil anos na Índia para controle de insetos pragas, nematóides, alguns fungos, bactérias e vírus, na medicina humana e animal, na fabricação de cosméticos, reflorestamento, como madeira de lei, adubo, paisagismo (NEVES et al. 2003).

Compostos químicos sintéticos têm sido o principal meio de controle de pragas. Apesar de sua contribuição para a produção agrícola, seu uso intensivo e indiscriminado favoreceu o surgimento de pragas secundárias, sem se conseguir eliminar os problemas já existentes. Além disso, são altamente tóxicos e prejudiciais ao ambiente e à saúde humana (MARQUES et al. 2004).

Compostos de origem vegetal, portanto, podem se constituir em importantes agentes de controle, pela fácil obtenção e utilização, pelo baixo custo e por minimizarem os problemas apresentados pelos produtos químicos sintéticos. Extratos biologicamente ativos, obtidos de folhas, frutos, sementes e do tronco de nim (Azadirachta indica A. Juss.), são reconhecidos pelas múltiplas propriedades terapêuticas, inseticidas, nematicidas e fungicidas (MOSSINI; KEMMELMEIER, 2005), sendo a azadiractina considerada o composto ativo mais potente da árvore de Nim (BUTTERWORTH; MORGAN, 1968). As vantagens do nim em relação a outras plantas inseticidas são a atividade sistêmica, a eficiência em baixas concentrações, a baixa toxicidade a mamíferos e a menor probabilidade de desenvolvimento de resistência pela ocorrência de um complexo de princípios ativos (VENDRAMIM; CASTIGLIONI, 2000).

$\mathrm{O}$ nim tem sido mundialmente estudado quanto ao seu potencial inseticida, de maneira que seus extratos têm se revelado tão potentes quanto alguns inseticidas comerciais, principalmente em relação aos lepidópteros, que são os mais sensíveis às substâncias derivadas do nim (SCHMUTTERER, 1990). 
Segundo Martinez (2000), o nim é conhecido há 5 mil anos e apresenta ação contra mais de 430 espécies de pragas que ocorrem em diversos países, causando inúmeros efeitos, tais como

repelência, interrupção do desenvolvimento, atraso no desenvolvimento, redução na fertilidade e fecundidade e várias outras alterações no comportamento e na fisiologia dos insetos que podem levá-los à morte. Esta árvore apresenta uma série de compostos limonóides, dentre os quais a azadiractina é o que ocorre em maior concentração e que apresenta maior atividade tóxica contra insetos. É utilizado principalmente na forma de extratos aquosos ou orgânicos. Inúmeros trabalhos foram desenvolvidos por pesquisadores, avaliando a efetividade de extratos oriundos de diversas partes da planta de nim no combate a pragas, fungos e bactérias que atacam as mais diversas culturas alimentícias, a exemplo do tomate, café, couve e outras (SAITO et al. 2004; MOURÃO et al. 2004; COITINHO et al., 2006; DINIZ et al. 2006; SANTOS et al. 2006; TORRES et al. 2006; VILLAR-GONZÁLES et al. 2006).

As sementes de nim, em condições normais, apresentam baixa longevidade (cerca de dois meses), exibindo um comportamento intermediário no armazenamento. (NEVES et al. 2003; HONG e ELLIS, 1998). Segundo Ezumah (1986), a germinação é afetada negativamente por temperaturas acima de $30{ }^{\circ} \mathrm{C}$. Os frutos maduros são de coloração amarelada e a polpa, doce e comestível, bastante parecida com o sabor do café no estágio cereja (NEVES et al. 2003).

Um fator que exerce grande influência sobre a germinação de sementes é o seu grau de maturação na ocasião da colheita. Sementes quando colhidas imaturas apresentam vigor e poder germinativo baixos (ALVARENGA et al. 1984). Este problema é maior em frutos carnosos, devido à dificuldade de se conhecer a época em que ocorre a maturação fisiológica das sementes, já que nem sempre há necessidade de se esperar a completa maturação visual (ALVARENGA et al. 1991). Segundo Capelanes e Biella (1985), frutos de espécies frutíferas são geralmente coletados quando estão com a coloração amarela, vermelho-escura, marrom-escura ou quando se apresentam moles ao tato. Outro fator que também influencia a germinação de sementes é o método de obtenção das sementes e/ou frutos, se no chão ou diretamente na árvore.

No caso do nim, não foram encontradas informações sobre métodos de obtenção das sementes e nem sobre o grau de maturação dos frutos, tendo como base a sua coloração. As poucas informações existentes dizem respeito às condições mais adequadas para a germinação de suas sementes, a exemplo do trabalho desenvolvido por Vidigal et al. (2007). Como foram 
mencionados anteriormente, esses são fatores que exercem influência sobre a germinação, pois podem estar relacionados com a maturidade fisiológica da semente.

Diante do exposto, este trabalho teve como finalidade avaliar a qualidade fisiológica de sementes de nim em função do tipo de coleta, se no chão ou na árvore e em função da coloração dos seus frutos.

\section{MATERIAL E MÉTODOS}

O ensaio foi conduzido no Laboratório de Sementes da Universidade Estadual Paulista Jaboticabal-SP. Os frutos de nim foram coletados em maio de 2008 no Campus de Jaboticabal, sob duas formas de coleta (na árvore e no chão), apresentando externamente as seguintes condições: T1- na árvore apresentando coloração verde; T2- no chão, apresentando polpa; T3- no chão, com resquícios de polpa; T4- na árvore de coloração amarela; T5- na árvore em diferentes colorações. Em laboratório, os frutos coletados na árvore foram despolpados com o auxílio de uma peneira em água corrente sendo, em seguida, colocados à sombra sobre folha de papel germitest durante uma semana. Em relação aos frutos coletados no chão, parte encontrava-se parcialmente sem polpa. Ambos foram também lavados e postos pra secar a temperatura ambiente até a semeadura. Previamente ao teste de germinação, foi determinado o teor de água dos frutos e das sementes de todos os tratamentos, em estufa regulada a $105^{\circ} \mathrm{C} \pm 3$, utilizando duas repetições de 10 frutos e sementes por tratamento, respectivamente. Quanto ao teste de emergência, a semeadura foi efetuada em caixas gerbox, contendo areia autoclavada, em germinador à temperatura alternada de $20-35^{\circ} \mathrm{C}$. Utilizaram-se quatro repetições de vinte sementes por tratamento, com exceção do tratamento de coloração amarela que possuiu quatro repetições de quinze sementes. As observações foram realizadas durante um período de 21 dias, iniciando-se a partir do oitavo dia após semeadura, quando da emergência do hipocótilo sobre o substrato. As características avaliadas foram percentagem e índice de velocidade de emergência (IVE), segundo fórmula de Maguire (1962) e percentagem de plântulas normais.

O delineamento estatístico utilizado foi inteiramente casualizado, empregando-se o teste F para a análise de variância dos dados. As médias foram comparadas pelo teste de Tukey a 5\% de probabilidade. 


\section{RESULTADOS E DISCUSSÃO}

Os dados médios sobre o teor de água dos frutos e das sementes encontram-se na Tabela 1.

Tabela 1. Dados médios do teor de água (\%) de frutos e de sementes de nim (Azadirachta indica A. JUSS) coletados na árvore e no chão. Jaboticabal, SP. 2008.

\begin{tabular}{|c|c|c|}
\hline \multirow{2}{*}{ TRATAMENTOS } & \multicolumn{2}{|c|}{ TEOR DE ÁGUA (\%) } \\
\hline & FRUTOS & SEMENTES \\
\hline T1-árvore/verdes & 74 & 40 \\
\hline T2-chão/com polpa & 37 & 17 \\
\hline T3-chão sem polpa & 39 & 19 \\
\hline T4-árvore/amarelo & 60 & 36 \\
\hline $\begin{array}{l}\text { T5-árvore/ mistura de } \\
\text { frutos }\end{array}$ & 67 & 43 \\
\hline
\end{tabular}

Os frutos coletados na árvore (Tabela 1) sejam de coloração verde, amarela e frutos misturados, apresentaram os maiores percentuais de teor de água, na ordem de 74, 60 e 67\%, respectivamente. Enquanto que os frutos coletados no chão, por não estarem mais ligados à planta mãe e que, por essa razão, já sofreram desidratação, exibiram percentuais mais reduzidos, na ordem de 37 e $39 \%$ para os tratamentos T2 e T3. Quanto aos teores de água das sementes (Tabela 1), os valores variaram de 17 a $43 \%$, sendo que os menores teores de água foram alcançados para as sementes coletadas no chão.

Na Tabela 2 encontram-se os dados de análise de variância das características avaliadas (emergência, IVE e plântulas normais). Houve significância a $1 \%$ de probabilidade pelo teste $\mathrm{F}$ para todas as características avaliadas. 
Tabela 2. Análise de variância da germinação (\%), índice de velocidade de emergência e plântulas normais (\%) de sementes de nim (Azadirachta indica A. JUSS) provenientes de frutos em diferentes pontos de coleta.

\begin{tabular}{l|c|c|c|c}
\hline \multirow{2}{*}{ Fontes de variação } & \multicolumn{4}{|c}{ Quadrados Médios } \\
\cline { 2 - 5 } & GL & Germinação & IVE & Plântulas Normais \\
\hline Tratamentos & 4 & $242,3605^{* *}$ & $0,2589 * *$ & $141,4325^{* *}$ \\
Resíduo & 15 & 36,1697 & 0,0084 & 26,3542 \\
\hline CV $(\%)$ & & 18 & 16 & 16 \\
\hline
\end{tabular}

** significativo a $1 \%$ de probabilidade pelo teste $\mathrm{F}$.

A maior percentagem de emergência de sementes de nim (50\%) foi obtida quando os frutos foram coletados no chão, mas que apresentavam resquícios de polpa, diferindo dos demais tratamentos, os quais apresentaram valores de germinação abaixo de 30\% (Figura 1). Neste tratamento, verificou-se a presença de restos de polpa aderida à semente, levando a inferir que, por estarem no chão, morcegos e/ou roedores, comuns no local de coleta, teriam se alimentado dos frutos e favorecido indiretamente a germinação das sementes por ter provocado algum tipo de injúria no endocarpo do fruto. 


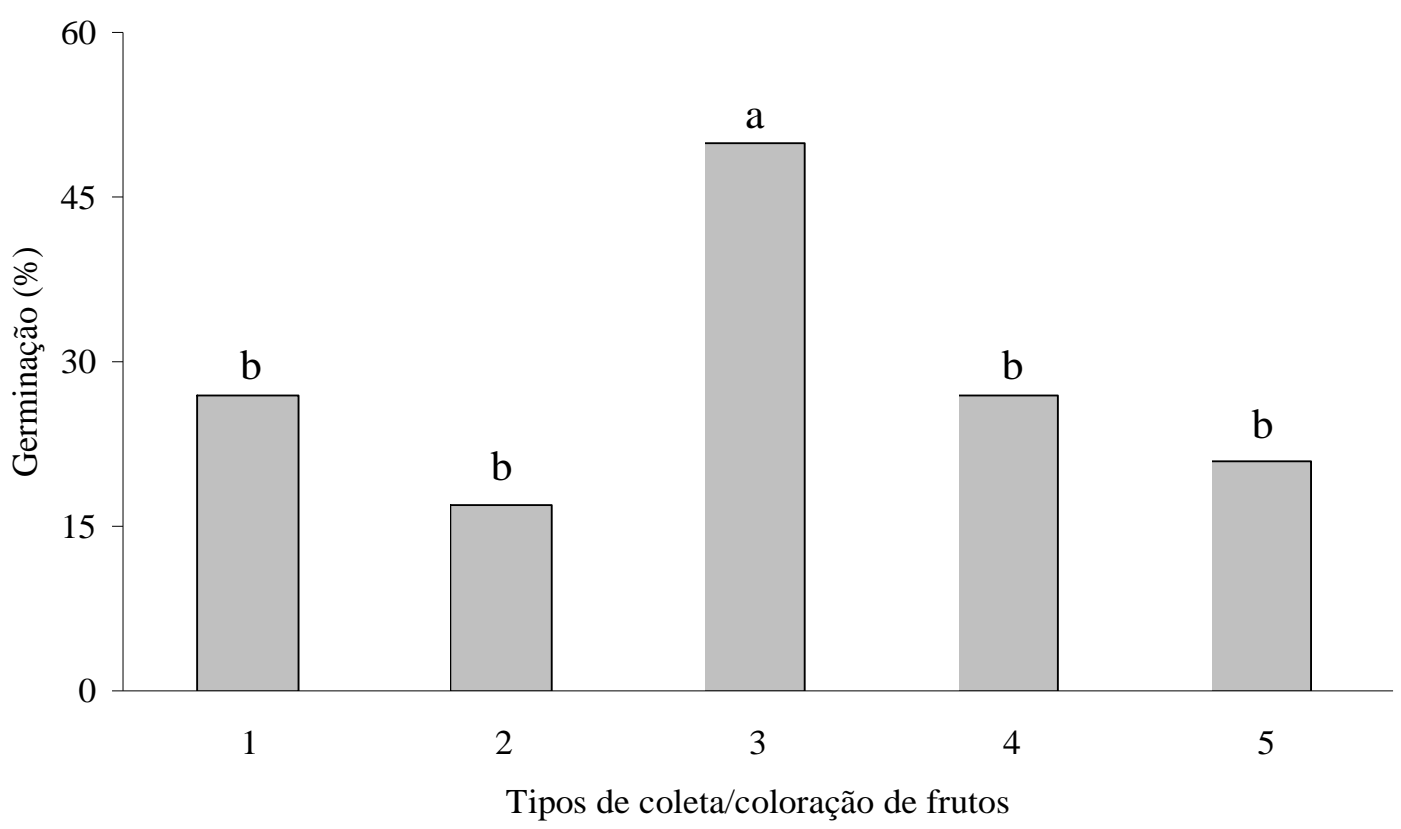

Figura 1. Emergência de plântulas de nim (Azadirachta indica A. JUSS) provenientes de frutos em diferentes pontos de coleta. (T1- árvore/verdes; T2- chão/com polpa; T3- chão com resquício de polpa; T4árvore/amarelo; T5- árvore/mistura de frutos.

O percentual de germinação das sementes obtido nesta pesquisa (Figura 1) foi semelhante ao encontrado por Vidigal et al (2007), ao avaliarem o efeito de substratos e temperaturas na germinação de sementes de nim. Os autores obtiveram 52\% e 50\% de germinação nos substratos vermiculita e rolo de papel, respectivamente, à temperatura de $35{ }^{\circ} \mathrm{C}$. Fonseca et al. (2006) estudaram a taxa de germinação de sementes de Parapiptadenia psilostachya, colhidas na copa e coletadas no chão da floresta, e verificaram que não houve diferença significativa entre ambos os métodos, sendo recomendada, portanto, a coleta de frutos que caíram no chão por ser de execução mais fácil do que escalar a matriz para obter frutos diretamente na copa.

Existem controvérsias quanto ao método de obtenção de sementes, se na árvore, se no chão. O importante é que a escolha de um método de obtenção das sementes deve ser eficiente e fornecer sementes de boa qualidade. A colheita diretamente na copa e não a coleta com uso de panos estendidos no chão ou sobre o solo é recomendada por LONGMAN (2003). Segundo esse autor, o primeiro método reduz a taxa de predação e remoção dos frutos, evita que as sementes se percam ou acumulem umidade e possibilita a identificação segura da árvore-mãe. Além disso, em espécies com frutos deiscentes e sementes aladas pode ser difícil obter número satisfatório de sementes no chão e aquelas presentes em frutos que caíram antes de se abrir podem não 
apresentar embrião suficientemente desenvolvido. No caso de árvores de dossel ou emergentes, contudo, a colheita na copa envolve a escalada das matrizes, e é freqüentemente de difícil execução. Nesses casos, uma comparação da taxa de germinação de sementes obtidas por diferentes métodos é essencial para a avaliação dos custos e benefícios de cada um.

Em relação ao IVE (Figura 2), o comportamento foi semelhante, ou seja, as sementes que foram oriundas de frutos coletados no chão e com resquícios de polpa apresentaram o maior índice de velocidade de germinação $(0,95)$, diferindo estatisticamente dos demais. Os menores índices foram exibidos pelos tratamentos "chão com polpa" e "árvore/mistura". Em sementes de cerejeira, o vigor foi maior quando as sementes foram oriundas de frutos de coloração preta e coletadas no chão, apresentando a melhor qualidade fisiológica (FIRMINO et al. 1996).

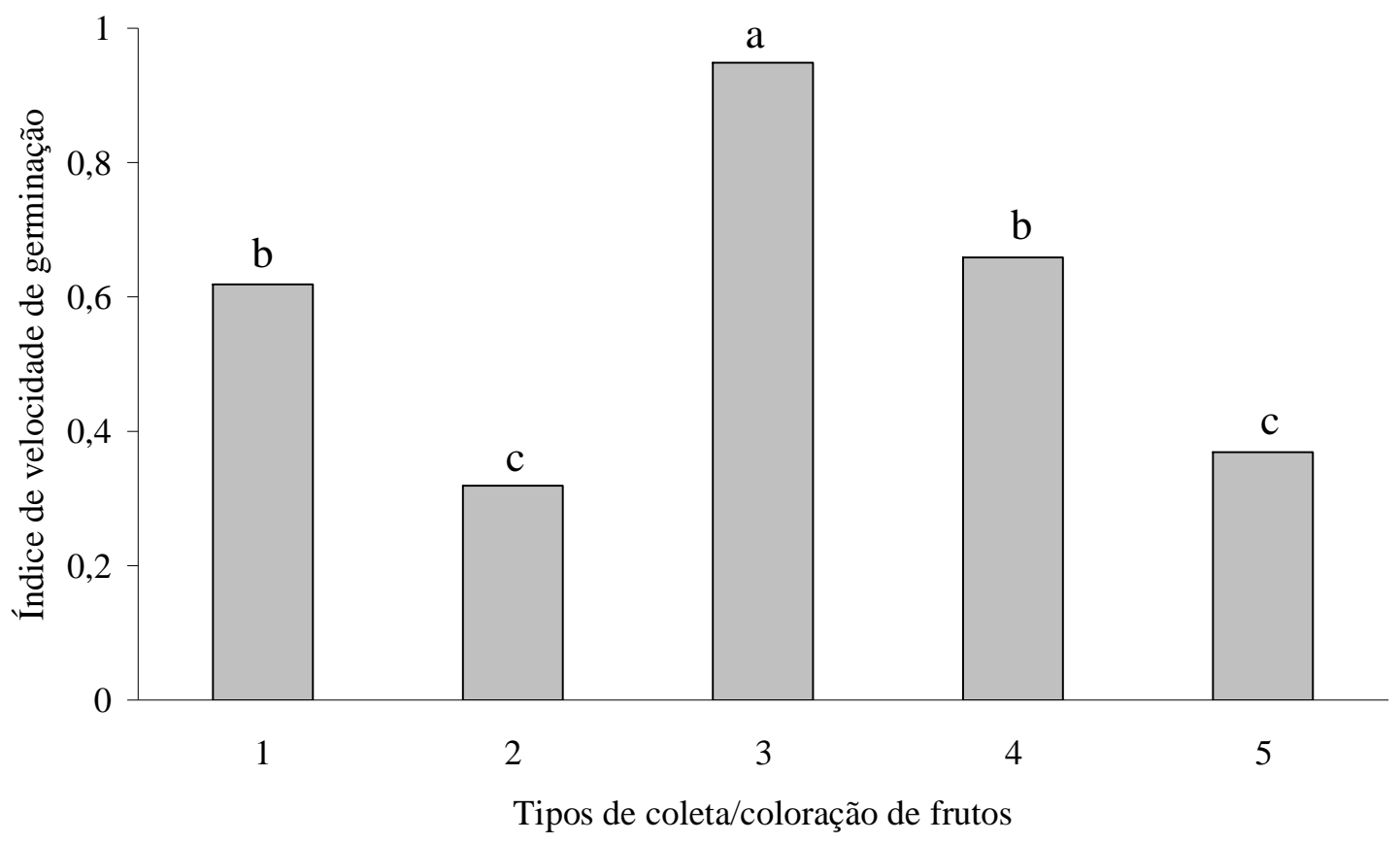

Figura 2. Índice de velocidade de emergência de plântulas de nim (Azadirachta indica A. JUSS) provenientes de frutos em diferentes pontos de coleta. (T1- árvore/verdes; T2- chão/com polpa; T3- chão com resquício de polpa; T4-árvore/amarelo; T5- árvore/mistura de frutos.

No que se refere à percentagem de plântulas normais (Figura 3), o T3 (coletados no chão com restos de polpa) obteve maior percentagem (40\%), porém, não diferindo significativamente dos tratamentos T4 e T5. 


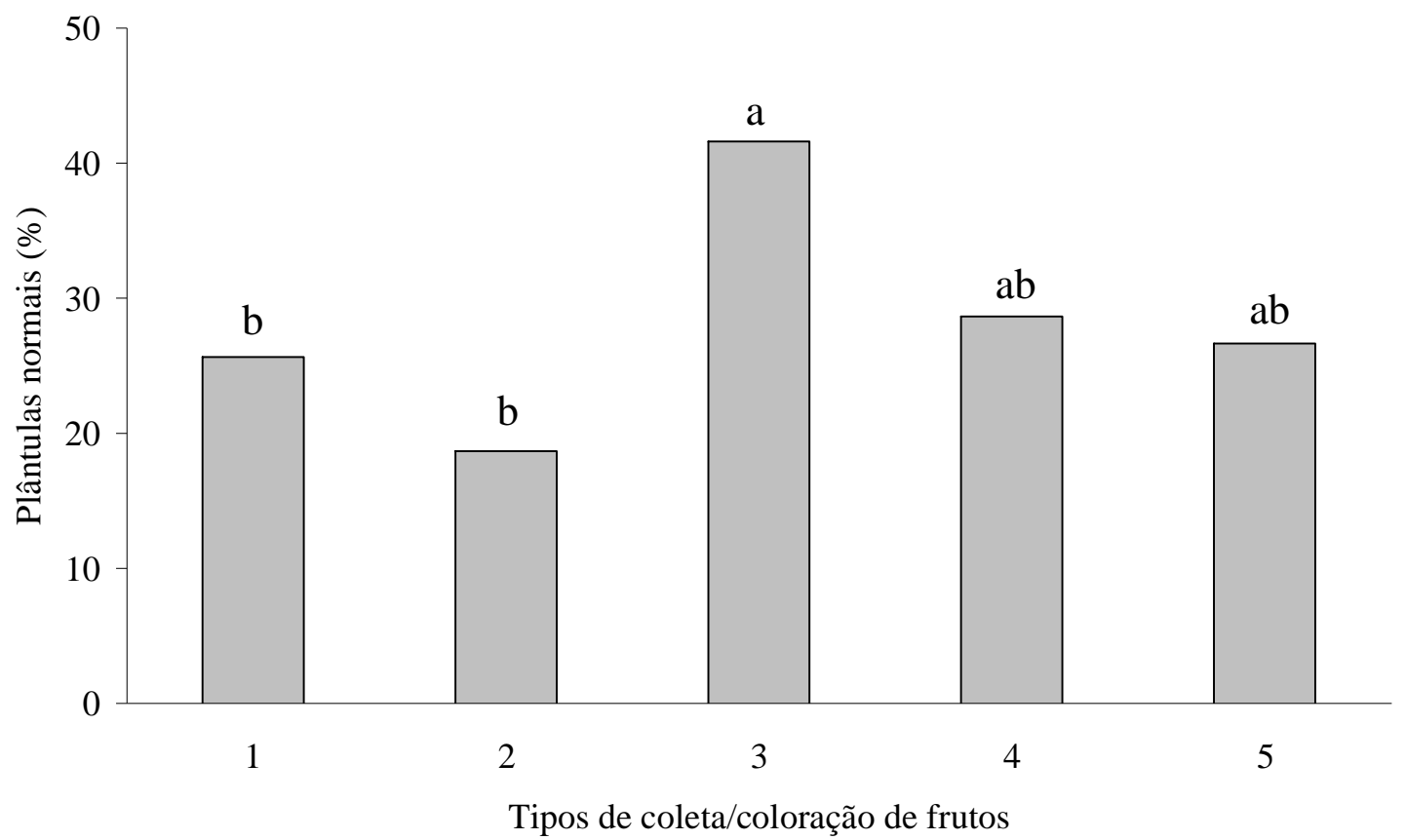

Figura 3. Plântulas normais (\%) de nim (Azadirachta indica A. JUSS) provenientes de frutos em diferentes pontos de coleta (T1- árvore/verdes; T2- chão/com polpa; T3- chão com resquício de polpa; T4árvore/amarelo; T5- árvore/ mistura de frutos.

Observou-se, nesta pesquisa, que o método de obtenção dos frutos associado à coloração desses é um parâmetro importante que deve ser levado em consideração na coleta de frutos de nim para avaliar a qualidade de suas sementes.

De acordo com Nayal et al. (2002), os frutos de nim atingem a maturidade nove semanas após a antese, quando se verifica uma mudança de coloração do verde para o amarelo róseo, iniciando a queda dos frutos. Assim, outros trabalhos deveriam ser realizados acompanhando o processo de maturação dessa espécie para verificar quando essa atinge a maior qualidade fisiológica.

\section{CONCLUSÃO}

Sementes de nim, oriundas de frutos coletados no chão, que se apresentavam parcialmente com polpa, exibiram maior qualidade fisiológica. 


\section{REFERÊNCIAS}

ALVARENGA, E. M; R. F. SILVA; ARAÚJO, E. F. Influência da idade, armazenamento póscolheita dos frutos na qualidade fisiológica. Horticultura Brasileira, v.2, p.5-8. 1984.

ALVARENGA, E. M; R. F. SILVA.; ARAÚJO, E. F. Maturação fisiológica de sementes de abóbora italiana. Revista Brasileira de Sementes, v.13, p.147-50. 1991.

BUTTERWORTH, J. H; MORGAN, E. D. Isolation of a substance that supresses feeding in locusts. Journal of the Chemical Society, London, v.35, n.1, p.23-24, 1968.

CAPELANES, T. M. C; BIELLA, L. C.. Programa de produção e tecnologia de sementes de espécies florestais nativas desenvolvido pela companhia energética de São Paulo - CESP. p.85107. In Simpósio Brasileiro sobre Tecnologia de Sementes Florestais, 1. Belo Horizonte-MG. 450 p. Anais... 1985.

COITINHO, R. L. B. de C et al. Atividade inseticida de óleos vegetais sobre Sitophilus zeamays mots. (Coleoptera: Curculionidae) em milho armazenado. Caatinga, Mossoró, v.19, n.2, p.176182, abr./jun., 2006.

DINIZ, L. P et al. Avaliação de Produtos Alternativos para Controle da Requeima do tomateiro. Fitopatologia Brasileira, v. 31, n.2, 2006.

EZUMAH, B. S. Germination os storage of neem (Azadirachta indica A. Juss) seed. Seed Science and Technology, n.14, p. 593-600, 1986.

FIRMINO, J. L; SANTOS, D. S. S. dos; SANTOS FILHO, B.G. dos. Características físicas e fisiológicas de sementes e plântulas de cerejeira (Torresia acreana Ducke) quando as sementes foram coletadas do chão ou do interior do fruto. Revista Brasileira de Sementes, v. 18, n.1, p. 28-32, 1996.

FONSECA, M. G; LEÃO, N. V. M; SANTOS, F. A. M.dos. Germinação de sementes e crescimento inicial de plântulas de Pseudopiptadenia psilostachya (DC.) G.P.Lewis \& M.P.Lima (Leguminosae) em diferentes ambientes de luz. Revista Árvore, Viçosa, v.30, n.6, p.885-891, 2006.

HONG, T. D; ELLIS, R. H. Contrasting seeds storage behaviour among different species of Meliaceae. Seed Science and Technology, Zürich, v.26, n.1, p.77-95, 1998.

LONGMAN, K. A. Raising seedlings of tropical trees. Londres: Commonwealth Science Council, 2003. 156 p. 
MAGUIRE, J. D. Speed of germination aid in selection and evaluation for seedling emergence and vigor. Crop Science, Madison, v.2, n.1, p.176-177, 1962.

MARQUES, R P; MONTEIRO, A. C; PEREIRA, G. T. Crescimento, esporulação e viabilidade de fungos entomopatogênicos em meio contendo diferentes concentrações de óleo de Nim (Azadirachta indica). Ciência Rural, Santa Maria, v.34, n.6, p.1675-1680, 2004.

MARTINEZ, S. S. O Nim - Azadirachta indica - natureza, usos múltiplos, produção. Londrina: IAPAR, 2002. 142p.

MOSSINI, S. A. G; KEMMELMEIER, C. A árvore Nim (Azadirachta indica. A. Juss.): múltiplos usos. Acta Farmaceutica Bonaerense, Buenos Aires, v.24, n.1, p.139148, 2005.

MOURÃO, S. A et al. Toxicidade de extratos de nim (Azadirachta indica) ao ácaro-vermelhodo-cafeeiro Oligonychus ilicis. Pesquisa Agropecuária Brasileira, Brasília, v.39, n.8, p.827830, ago. 2004.

NAYAL J. S et al. Effect of maturation stage on the longevity of neem (Azadirachta indica A.Juss.) seed. Seed Science and Technology, Zürich, v.30, n.3, p. 621-628, 2002.

NEVES, B. P. DAS; OLIVEIRA, I. P. de; NOGUEIRA, J. C. M. Cultivo e Utilização do Nim Indiano. Santo Antônio de Goiás, GO, Dezembro, 2003 (Circular Técnica, 62).

SAITO, M. L et al. Avaliação de plantas com atividade deterrente alimentar em Spodoptera frugiperda (J.E.SMITH) e Anticarsia gemmatalis HUBNER. Pesticidas: Revista Ecotoxicologia e Meio Ambiente, Curitiba, v.14, p.1-10, 2004.

SANTOS, A. C. G. DOS et al. Uso de Extrato de Nim no Controle de Acaríase por Myobia musculi Schranck (Acari: Miobidae) e Myocoptes musculinus Koch (Acari: Listrophoridae) em Camundongos (Mus musculus var. albina L.). Neotropical Entomology, v35, n.2 p.269-272, 2006.

SCHUMUTTERER, H. Properties and potential of natural pesticides from the nim tree, Azadirachta indica. Annual Review of Entomology, Palo Alto, v. 35, p. 271-297, 1990.

SOON, I. G; BOTTRELL, D. G. Neem pesticides in rice: potential and limitations. Manila: International Rice Research Institute, 1994. 69p.

TORRES, A. L et al. Efeito de extratos aquosos de Azadirachta indica, Melia azedarach e Aspidosperma pyrifolium no desenvolvimento e oviposição de Plutella xylostella. Bragantia, Campinas, v.65, n.3, p.447-457, 2006. 
VENDRAMIM, J. D; CASTIGLIONI, E. Aleloquímicos, resistência de plantas e plantas inseticidas. In: GUEDES, C. et al. (Org.). Bases e técnicas do manejo de insetos. Santa Maria: UFSM/CCR/DFS, 2000. p.113-128.

VIDIGAL, D. de S; BRASILEIRO, B. G; DIAS, D. C. F. S. Germinação e morfologia do desenvolvimento pós-seminal de sementes de nim-indiano (Azadirachta Indica A. Juss. Meliaceae). Revista Brasileira de Sementes, vol. 29, n. 3, p. 39-46, 2007.

VILLAR-GONZÁLEZ, D. DEL; VILLANUEVA-JIMÉNEZ, J. A; MARTÍNEZ-BECERRIL, C. Repelencia alimenticia de extractos de éter etílico de nim (Azadirachta indica) en arroz palay, para el control del tordo ojirrojo (Molothrus aeneus). Agrociencia, v. 40, n. 2, p. 197-203. 2006. 